\title{
Research and Design of CCHP System in Mechanical Industry
}

\author{
Ming $\mathrm{Li}^{1}$, Zheng Wang ${ }^{1}$ \\ ${ }^{1}$ Chongqing Vocational Institute of Engineering, Chongqing, 400052, China
}

\author{
Keywords: Mechanical industry. CCHP. System. Study. Design
}

\begin{abstract}
For the machinery industry, which belongs to the energy industry consumption of large-scale, for future development, plays a decisive role in crucial. Along with the environmental protection idea unceasingly thorough, energy production has gradually been recognized by more and more enterprises. In the machinery industry, realize the design and development of CCHP system, is to promote an important technology of energy-saving industry production. For the development of industrial core technology in the future, energy-saving production gives strong theoretical support. This paper focuses on the analysis in mechanical industry, development and design of the CCHP system.
\end{abstract}

\section{Introduction}

Combined Cooling Heating and Power system called CCHP in English for short is developed on basis of the CHP system. With the development of industrial levels, CHP system is rarely used except for some small ones. On the contrary, CCHP system with higher energy utilization rate draws more and more attention. CCHP is a system which organically integrates heating, cooling and power. At present, CCHP system is widely applied in supporting facilities like heating and power for residential districts but rarely in engineering industry especially in China. Chinese engineering industry at the very beginning stage is able to realize that this system can save a large amount of energy, accord with present development pattern of low carbon economy and ensure an enterprise's continuable development by researching on the application of CCHP system in some western developed countries' engineering industry.

\section{Description of CCHP system}

Western developed countries studied out CHP system in order to increase energy utilization rate, while scientific and technological progress caused the appearance of CCHP system which has been widely applied in each industry and field nowadays. CCHP system organically integrates heat utilization technology and distributed generation technology, and increases energy utilization rate to the greatest extent through its application. At present, CCHP system in the world is developed best in Denmark. Denmark has become the country of the highest energy utilization rate with the usage of this system. Western developed countries under pressure of energy crisis and environmental crisis start to energetically increase their own energy utilization rate. The best way of increasing energy utilization rate is to develop CCHP system. With the usage of this system, the energy utilization rate of developed countries like Germany and England has become above 50\% but Chinese energy utilization rate is still less than $40 \%$.

The operating principle of CCHP system is in fact rather simple. It is driving the electric generator to generate electricity through fuel combustion, changing the high-temperature gas after burning into hot-gas, hot water or cool gas through equipment like boiler and refrigerating machine, and providing people with the hot-gas, hot water and cool gas. In engineering industry, the high-temperature gas after burning can also be offered to industrial production and refrigerating machine system. The energy utilization rate can be greatly increased through the cyclic utilization of energy like this. CCHP system has no strict requirement for fuel, and can adopt marsh gas, natural gas, etc. It usually adopts natural gas as its fuel in the daily usage. 


\section{Design features of CCHP system}

Compared with traditional energy supply modes, CCHP system has distinctive features. Firstly, this system effectively avoids problems caused by for the reason that it is able to supply power for itself. Sudden power failure will bring great impact on production especially in engineering industrial production. Secondly, it is in the aspect of air conditioning usage. When the weather is hot, central air-conditioning is currently used to lower indoor temperature. Engineering industrial environment, compared with common office buildings, has more requirements for air conditioning, but the usage of air conditioning will definitely cause electric tension. CCHP system is able to directly supply energy for air conditioning system, which greatly reduces the load of power grid in summer the peak season. The last feature of CCHP system is increasing energy utilization rate. The energy utilization rate of traditional fuel machine is usually $40 \%$, but CCHP system can reach $80 \%$, which shows this system's increasing effects of energy utilization rate.

Even though CCHP system has so many advantages, there still exist some problems in its development process. Firstly, CCHP system started late in China, so there is a large gap between China and western developed countries in aspects of technology and experience. These have to some extent affected the development of CCHP system in China. Secondly, at the early stage of CCHP system's usage, there must be a certain amount of input for the installation and update of equipment. Although it as a great benefit in the long run can increase energy utilization rate, many enterprises are not willing to invest for consideration of benefits, which also to a certain degree influences CCHP system's development in China. At last, CCHP system is a comparatively new technical project, and its installation, operation and debugging all have high requirements for technicians' quality. There are few relevant talents in China, which severely restricts the development of CCHP system in China.

\section{Application and design of CCHP system in engineering industry}

Engineering industry is a sign of measuring a country's industrial culture. China as an industrial power has engineering industries of large scale all over the country, but engineering industry consumes more energy than other industries. If CCHP system can be applied into engineering industry, it will bring even better energy-saving effects especially when green power and low carbon economy are strongly advocated. All enterprises are taking measures to reduce pollutant emission and increase energy utilization rate under pressure of public opinion and government policies. CCHP system can rightly meet these enterprises' requirements of sustainable development, so it is a necessity of both the engineering industry development and the times development.

The application of CCHP system in engineering industry is mainly providing power system for engineering industry production and energy for air conditioning system. Present engineering industry is automated or semi-automated production, automated engineering industry production needs massive power energy and the power of engineering industry production basically comes from electric power. Therefore, these will increase burden for regional power grid and cause strong power grid dependence. If power failure problems suddenly happen, the production of engineering industry can no longer continue. If adopting CCHP system, enterprises of engineering industry production can set up their own power generation department and form a self-sufficient energy supply mode by purchasing gas turbine generators. The exhaust gas caused by gas turbine generators in this system can also be turned to hot water and hot gas through special boilers and supply heating for factories in winter. Such kind of cyclic utilization of fuel gas increases its utilization rate to the greatest extent.

At the initial stage of system establishment, enterprises need to purchase relevant equipment such as gas turbine generators and boilers. The input will increase enterprises' investment in the short run, but if considering in a long run, enterprises will eliminate the cost of electricity consumption by adopting this system in engineering industry. Through the statistical survey of western developed countries' engineering industry, enterprises can regain their cost in several years after installing this system. Some enterprises even combine with public power grid. When this system generates comparatively more electricity, it can supply power for public power grid and the power grid 
company will cover the cost. Because of public power grid technology problems, such kind of cooperative mode can't be realized in China at present. Engineering industry enterprises can also achieve long-term benefits with short-term investment by using this system. At the same time, the low carbon economy development mode with high energy utilization rate accords with enterprises' concept of sustainable development and scientific development in new period.

\section{Application research on CCHP system in engineering industry}

Essentially, CCHP system is to localize the wide-area power grid and to turn the traditional large-scale power stations into small-scale ones. As for large-scale power stations, both building and maintenance need a great deal of cost which will finally be included in electric charge. At the same time, the building of large-scale power stations is usually invested by countries or local government. The energy utilization rate of large-scale power stations is limited especially the heat power stations, because the exhaust gas after burning can't be well reused and the utilization rate of energy like fuel gas is limited. Turning large-scale power stations into small-scale ones is just like building a small power station in an industrial park which is able to maintain power and heating in the industrial park. Small-scale power stations cause less exhaust gas, have more convenient cyclic utilization for exhaust gas and can effectively increase the utilization rate of energy. It can be imagined that if every industrial park builds a small-scale power station of its own and sets up its own CCHP system through the latest technology, the burden of public power grid will be greatly relieved. The increasing of fuel gas utilization rate will inevitably cause reducing of polluted gas like carbon dioxide and win long-term benefits for enterprises.

\section{Analysis on the long-term significance of developing CCHP system in engineering industry}

With the rapid economic development at present, the environment and energy problem has been gradually put on the agenda of every country even the whole world. Energy conservation and saving type production mode are rather essential for future development. Aiming at the energy-saving exploitation and energy utilization, engineering industry belongs to industries that consume plenty of materials especially the utilization and consumption of energy. Therefore, using CCHP system in engineering industry is extremely beneficial to industrial development in the future. It realizes two important items namely heating in winter and cooling in summer through conversion of electrical energy. Energetically developing CCHP system in engineering industry is to develop engineering industry better and provide strong driving force for multinomial and saving type industry in the future.

\section{Conclusion}

CCHP system as a kind of emerging energy-saving mode in 21 century increases energy utilization rate to the greatest extent through cyclic utilization of energy like fuel gas, makes energy supply more flexible by turning large-scale power stations into small-scale ones, and organically integrates heating, cooling and power. In the supply process, it can adjust the proportion of heating, cooling and power to meet the needs of different users. At the same time, increasing of energy efficiency will reduce enterprises' cost. This paper conducts research and analysis on the application of CCHP system in engineering industry. It can be safely concluded that application of this system in engineering industry will bring enterprises long-term economic benefits and social benefits.

\section{References}

[1] Ren Tianyu, Chen Xi, Zhang Hua, Feng Lina, \& Wang Jianzhong, CCHP system on basis of Stirling engine, Fluid Machinery,2012(11),71-74 
[2] Yu Mei, Influence factors of fractional energy saving of gas CCHP, Hunan Agricultural Machinery: Academic Edition,2012(5),55-55

[3]Tang Zhengyan, Wang Xun, \& Li Cheng, Analysis on CCHP technology,Green Building, 2012(6), 52-55

[4]Jiang Runhua, Yang Xiaoxi, Yang Minlin, \& Yang Xiaoping, Application and development tendency of distributed CCHP technology of internal combustion engine, Energy-saving Technology, 2012(2),127-130 